\title{
Symmetric Multiple Carbohelicenes
}

\author{
Kenta Kato ${ }^{a}$ \\ Yasutomo Segawa*a,b \\ Kenichiro Itami*a,b,c \\ ${ }^{a}$ Graduate School of Science, Nagoya University, Chikusa, \\ Nagoya 464-8602, Japan \\ ysegawa@nagoya-u.jp \\ bJST-ERATO, Itami Molecular Nanocarbon Project, Chikusa, \\ Nagoya 464-8602, Japan \\ itami@chem.nagoya-u.ac.jp \\ c Institute of Transformative Bio-Molecules (WPI-ITbM), \\ Nagoya University, Chikusa, Nagoya 464-8602, Japan
}

Published as part of the 30 Years SYNLETT - Pearl Anniversary Issue
Received: 21.07.2018

Accepted after revision: 24.08.2018

Published online: 26.09 .2018

DOI: 10.1055/s-0037-1610283; Art ID: st-2018-a0462-a

License terms: cc)

Abstract This account focuses on the synthesis and structures of symmetric multiple carbohelicenes; i.e., fully fused polycyclic aromatic hydrocarbons containing two or more symmetric helicene moieties. Synergies of the multiplexed helicene structures within a $\pi$-system generate a number of local minima and transition states between each state. Based on recent studies on multiple helicenes, a systematic molecular design for further multiplexed symmetric helicenes is proposed in the last section of this article.

Key words nonplanar $\pi$-systems, polycyclic aromatic hydrocarbons, helicene, multiple helicene

\section{Introduction}

Helicenes are screw-shaped molecules defined as orthofused polycyclic aromatic compounds, in which all aromatic rings are arranged helically. ${ }^{1}$ This helical structure endows helicenes with chirality even though chiral centers are not present. Based on the helicity rule proposed by Cahn, Ingold, and Prelog in 1966, a right-handed helix is denoted as $P$ (plus) whereas a left-handed helix is denoted as $M$ (minus). ${ }^{2}$ Such helical $\pi$-systems exhibit high values for optical rotation and circular dichroism. ${ }^{1 \mathrm{~d}}$ Moreover, due to the fact that the intrinsic chirality involves a large polyaromatic template, carbohelicenes efficiently induce asymmetry and chirality in organic synthesis and in supramolecular chemistry. ${ }^{1 \mathrm{e}, 1 \mathrm{f}}$

The helicity of helicenes can be interconverted thermodynamically with an inversion barrier $(\Delta G)$ that depends on the number of fused benzene rings $(n)$. In their ground states (GSs), unsubstituted helicenes exhibit $C_{2}$ symmetry. ${ }^{3}$ The transition states (TSs) for the enantiomerization of

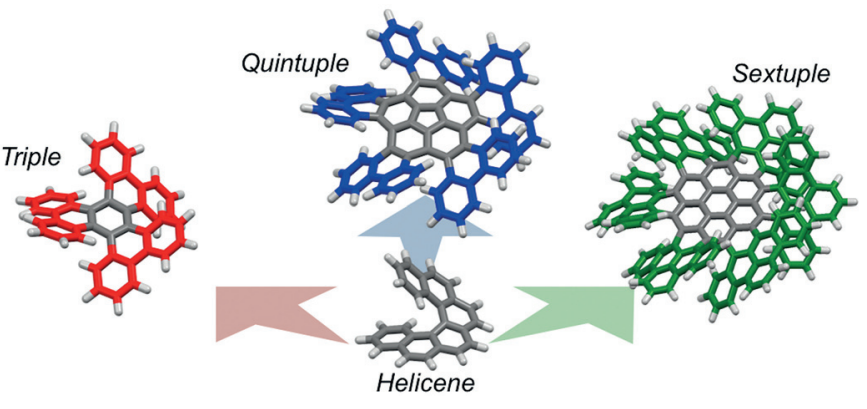

[ $n$ ]helicenes ( $n=4-7)$ are shown in Figure 1(a). In the case of [4] helicene, the TS adopts a planar $C_{2 v}$ symmetry with a barrier of $4.1 \mathrm{kcal} \cdot \mathrm{mol}^{-1}$, which is small enough for inversion at ambient temperature. The TSs for [5]-, [6]-, and [7]helicenes exhibit $C_{s}$ symmetry with barriers of 23.9, 37.3 , and $42.0 \mathrm{kcal} \cdot \mathrm{mol}^{-1}$, respectively (Figure $1(\mathrm{~b})$ ). The enantiomerization of $[n]$ helicenes $(n \geq 8)$ proceeds through multistep mechanisms with higher inversion barriers. ${ }^{3 a}$

(a) [4]helicene

$C_{2}$

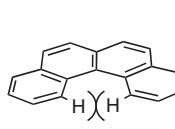

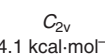

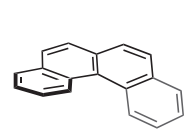

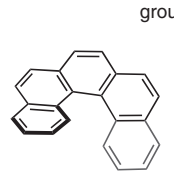

[5]helicene ground states

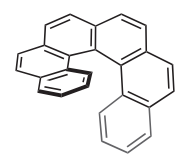

[6]helicene

$C_{2}$

transition states

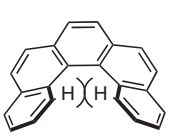

$C_{\mathrm{s}}$

$23.9 \mathrm{kcal} \cdot \mathrm{mol}^{-1}$

$\left(24.1 \mathrm{kcal} \cdot \mathrm{mol}^{-1}\right)^{3 \mathrm{c}}$

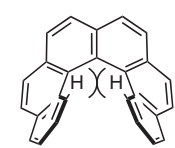

$C_{\mathrm{s}}$

$37.3 \mathrm{kcal} \cdot \mathrm{mol}^{-1}$

$\left(36.2 \mathrm{kcal} \cdot \mathrm{mol}^{-1}\right)^{3 \mathrm{~d}, \mathrm{t}}$
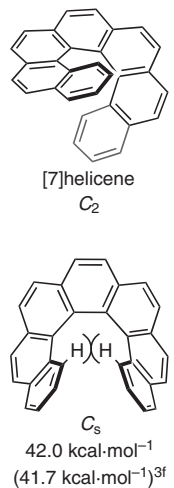

(b)

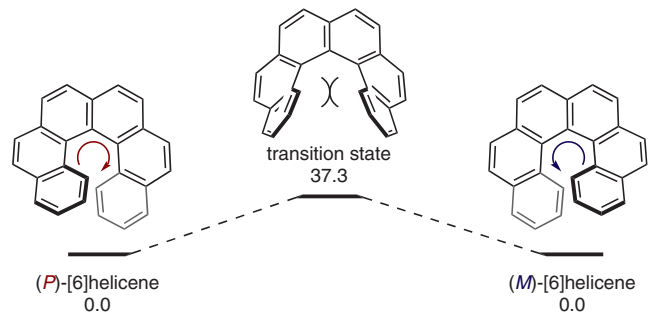

Figure 1 (a) Ground states and transition states of [ $n$ ] helicenes ( $n=4-$ 7) together with their symmetry and calculated inversion barriers. ${ }^{4} \mathrm{Ex}-$ perimentally determined inversion barriers are shown in parentheses. (b) Enantiomerization pathway from $(P)$ - to $(M)$-[6]helicene and its energy diagram $\left(\mathrm{kcal} \cdot \mathrm{mol}^{-1}\right){ }^{4}$ 
Owing to their inversion barriers, [5]helicene racemizes slowly at room temperature, whereas [6]helicene is stable at this temperature. For applications of helicenes in chiral materials, stable substances are required that do not racemize at ambient temperature. Hence, [6]helicene should be a suitable starting point for the design of thermally stable chiral materials.

For the construction of helicene derivatives, four approaches have been reported. The first approach affords helically elongated helicenes with a large number of orthofused benzene rings (Figure 2). ${ }^{5}$ Generating long helical structures remains challenging in synthetic chemistry, and currently the longest helicene is [16]helicene. ${ }^{5 e}$ The second approach generates laterally $\pi$-extended helicenes via a $\pi$ expansion in the vertical direction relative to its helical axis. ${ }^{6}$ The third approach furnishes heterohelicenes, in which some of the $\mathrm{sp}^{2}$-hydridized carbon atoms of carbohelicenes are replaced with heteroatoms such as $\mathrm{B}, \mathrm{N}, \mathrm{O}, \mathrm{Si}, \mathrm{P}$, or S. ${ }^{7-9}$ The optical properties of such heterohelicenes can be tuned by the inherent features of the heteroatoms (e.g., electronegativity, lone pairs, and structural characteristics). The fourth approach concerns multiple helicenes, which contain two or more helicene moieties in a $\pi$-conjugated system. ${ }^{10}$ Multiple helicenes exhibit highly distorted structures and unique thermodynamic properties that cannot be realized by single helicenes.

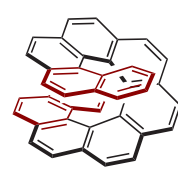

helically elongated helicenes

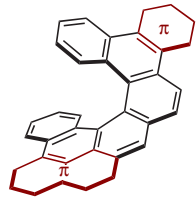

terally extended
helicenes

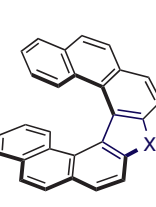

heterohelicenes

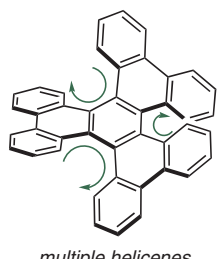

multiple helicenes
Figure 2 Four types of helicene derivatives

In this account, the synthesis and structures of symmetric multiple carbohelicenes are introduced. Multiple carbohelicenes are categorized by the number of their helicene moieties (multiplicity). With increasing number of helicene moieties, the stereochemistry and the isomerization path-

\section{Biographical Sketches}

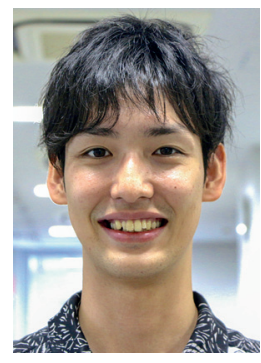

Kenta Kato was born in Aichi, Japan (1991). He obtained a Master degree in chemistry from Nagoya University in 2016. Currently, he is a postgraduate student in the group of Prof.
Kenichiro Itami, focusing on the synthesis of warped nanographenes.
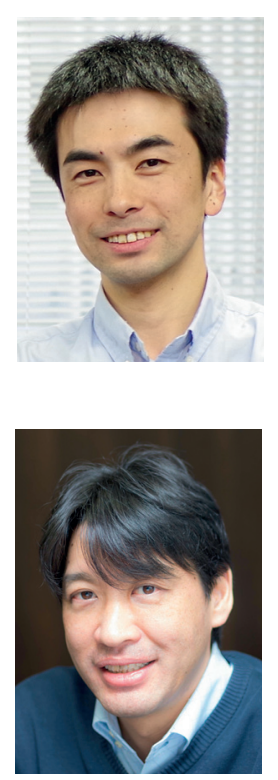

Yasutomo Segawa was born in Chiba, Japan (1982). He studied chemistry at The University of Tokyo, Japan, and completed his PhD in 2009 with Prof. Kyoko Nozaki. He then became an As- sistant Professor (with Prof. Kenichiro Itami) at Nagoya University in 2009, and became a Group Leader of JST-ERATO Itami Molecular Nanocarbon Project (Designated Associate
Professor, Nagoya University) in 2013. His research focuses on the synthesis of novel $\pi$-conjugated molecules having nontrivial topologies.
Kenichiro Itami was born in Pittsburgh, USA (1971) and raised in Tokyo. He studied chemistry at Kyoto University, Japan, and completed his $\mathrm{PhD}$ in 1998 with Prof. Yoshihiko Ito. After being Assistant Professor (with Prof. Jun-ichi Yoshida) at Kyoto University, he moved to Nagoya University as an Associate Professor (with Prof. Ryoji
Noyori) in 2005, where he was promoted to Full Professor in 2008. Since 2012 he has also been Director of the Institute of Transformative Bio-Molecules (WPI-ITbM) and since 2013 Research Director of JST-ERATO Itami Molecular Nanocarbon Project. His research focuses on the development of innovative functional molecules with sig- nificant structures and properties, and the development of rapid molecular-assembly methods using unique catalysts. Representative achievements are the creation of a range of structurally uniform nanocarbons of fundamental and practical importance by bottom-up chemical synthesis. 
ways of multiple helicenes become more complex. In this context, [4] helicene is not considered a helicene moiety, as the inversion barrier of such small helicenes is insufficient to stabilize the helicity. Multiple helicenes containing fivemembered rings, ${ }^{11}$ non-aromatic rings and/or heteroatoms $^{12}$ in the helicene structure are also not covered. Moreover, large unsymmetric polycyclic arenes containing helicene moieties are also excluded. ${ }^{13}$ In the final section, we present an outlook on multiple helicene chemistry and the further molecular design of highly multiplexed helicenes.

\section{Symmetric Double Carbohelicenes}

Symmetric double carbohelicenes contain two helicene moieties that are arranged symmetrically on a $\pi$-system. Due to the inherent two helical structures, symmetric double helicenes have three isomers: two enantiomers, the socalled twisted forms $[(P, P)$ and $(M, M)]$, and one diastereoisomer, the so-called meso form $(P, M)$. The first synthesis of double [5]helicene 1 was reported by Clar et al. in 1959. ${ }^{14}$ Ohshima, Sakamoto, and co-workers improved the synthesis of 1 by using a condensation reaction, and a twisted $D_{2}$ symmetric conformation was assigned (Figure 3(b)) based on ${ }^{1} \mathrm{H}$ NMR spectroscopy. ${ }^{15}$ Agranat and co-workers reported a computational study of $\mathbf{1}$ in $2007 .{ }^{16}$ S-shaped double [6] helicene 2 was synthesized by Laarhoven and Cuppen in 1971. ${ }^{17}$ Double helicene 2 was synthesized by a photocyclization reaction. The twisted and meso conformers of $\mathbf{2}$ were separated on account of their different solubility. Another type of double [6]helicene, having the shape of the figure of three (3) and its derivative (4) as a double [7]helicene, were synthesized by Martin et al. in 1974 using a photocyclization route. ${ }^{18}$ Based on the NMR and X-ray diffraction analysis of $\mathbf{3}$ and $\mathbf{4}$, twisted structures were assigned. In addition to these relatively old reports, three double carbohelicenes (5-7) have been reported in recent years. In 2015, Kamikawa and co-workers synthesized double [5]helicene 5 via a Suzuki-Miyaura cross-coupling reaction. ${ }^{19} \mathrm{X}$-ray diffraction analysis revealed the twisted structure of $\mathbf{5}$. The meso conformer of 5 is less stable by $5.7 \mathrm{kcal} \cdot \mathrm{mol}^{-1}$ than the twisted one, and the interconversion barrier of $\mathbf{5}$ was estimated to be $24.2 \mathrm{kcal} \cdot \mathrm{mol}^{-1}$. ${ }^{4}$ Double [6] helicene 6 was synthesized by Itami and co-workers in $2015,{ }^{20}$ and a mixture of the twisted and meso forms of $\mathbf{6}$ was obtained by a Scholl reaction. The three isomers were separated by HPLC, and Xray diffraction analysis revealed a three-dimensional $\pi-\pi$ stacking mode for the twisted isomer. The calculated racemization barrier $\left(43.5 \mathrm{kcal} \cdot \mathrm{mol}^{-1}\right)$ was too high for a kinetic study. Double [7]helicene 7, reported by Müllen and coworkers in 2017, was obtained as an unexpected product of a Scholl reaction of tetra-2-naphthyl-p-terphenyl. ${ }^{21}$ The most stable (twisted) and metastable (meso, $3.2 \mathrm{kcal} \cdot \mathrm{mol}^{-1}$ relative to the twisted conformer) conformers of 7 were iso- lated by recrystallization, and the racemization barrier of 7 was calculated to be $47.0 \mathrm{kcal} \cdot \mathrm{mol}^{-1}$.

The structures and enantiomerization pathway of symmetric double helicenes are shown in Figure 3(b) and Figure 3(c), where 1 was selected as a representative example. The most stable conformation of $\mathbf{1}$ is the $D_{2}$-symmetric twisted form (1a), while the $C_{2 h}$-symmetric meso conformation (1b) is metastable $\left(\Delta G=5.1 \mathrm{kcal} \cdot \mathrm{mol}^{-1}\right)$. The enantiomerization from 1a to $\mathbf{1 b}$ proceeds via the meso form and includes two chiral transition states $\mathbf{T S}_{\mathbf{1 a b}}$ and $\mathbf{T S}_{\mathbf{1 a}^{*} \mathbf{b}}\left(\mathbf{T S}_{\mathbf{1 X Y}}\right.$ : TS between $\mathbf{1 X}$ and $\mathbf{1 Y})$. In this pathway, the original chirality $(P, P)$ of 1a is lost upon transformation into the meso intermediate. The energy barrier for enantiomerization of $\mathbf{1}\left(31.7 \mathrm{kcal} \cdot \mathrm{mol}^{-1}\right)$ is higher than that of pristine [5]helicene. ${ }^{4}$ The inversion barriers of double helicenes 3-7 are also higher than those of the corresponding pristine [ $n$ ]helicenes, likely due to the structural interactions of two helicene moieties and the effect of the $\pi$-extension. (a)

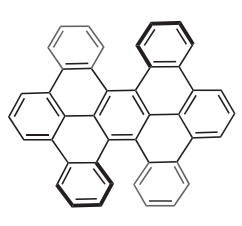
1
[5]helicenes $\times 2$ $31.7 \mathrm{kcal} \cdot \mathrm{mol}^{-1}$

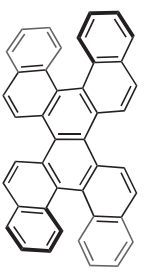
5 [5]helicenes $\times 2$ $24.2 \mathrm{kcal} \cdot \mathrm{mol}^{-1}$

(b)

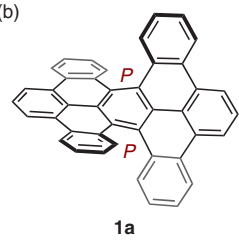

$D_{2}$

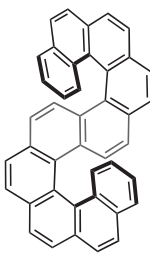

2

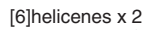
$34.6 \mathrm{kcal} \cdot \mathrm{mol}^{-1}$

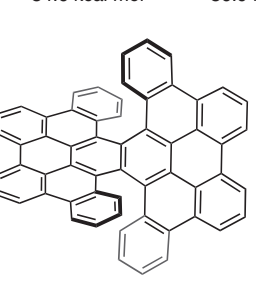

6

[6]helicenes $\times 2$ $43.5 \mathrm{kcal} \cdot \mathrm{mol}^{-1}$

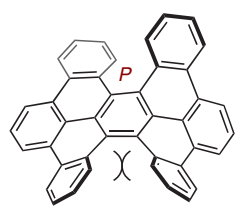

$\mathrm{TS}_{1 \mathrm{ab}}$

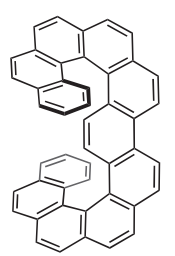

[6] helicenes $x 2$ $36.9 \mathrm{kcal} \cdot \mathrm{mol}^{-1}$
3

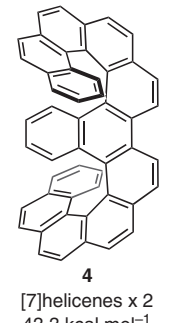

$43.3 \mathrm{kcal} \cdot \mathrm{mol}^{-1}$

$t \mathrm{Bu}$

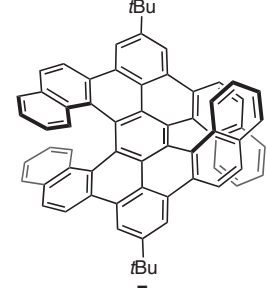

[7]helicenes $x 2$ $47.0 \mathrm{kcal} \cdot \mathrm{mol}^{-1}$

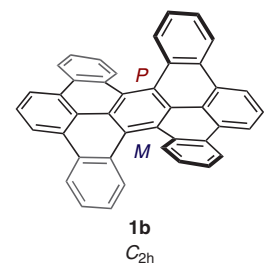

$C_{2 \mathrm{~h}}$ (c)

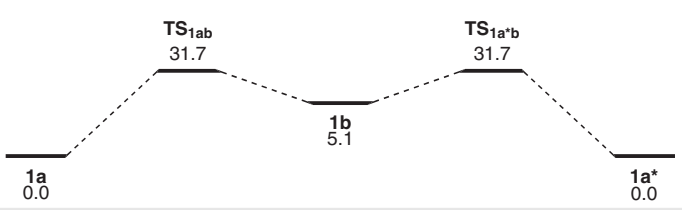

Figure 3 (a) Double helicenes with a racemization barrier. (b) Optimized conformers and transition structures of $\mathbf{1}$ with the helicity of the [5]helicene moieties ( $P$ or $M)$. (c) Racemization pathway of $\mathbf{1}$ with relative Gibbs free energy values $\left(\mathrm{kcal} \cdot \mathrm{mol}^{-1}\right){ }^{4}$ 


\section{Symmetric Triple Carbohelicenes}

Symmetric triple carbohelicenes have four isomers; i.e., two pairs of enantiomers $[(P, P, P)$ and $(M, M, M)$ as well as $(P, P, M)$ and $(P, M, M)]$. The most representative member of this class of multiple helicenes is triple [5] helicene $\mathbf{8}$, which has been well-studied by several groups. ${ }^{22}$ The first synthesis of $\mathbf{8}$ was reported by McOmie and co-workers in 1982 using flash vacuum pyrolysis of cyclobuta[l]phenanthrene1,2-dione. ${ }^{2 a}$ In 1999, two groups independently reported the synthesis of $\mathbf{8}^{22 \mathrm{~b}, 22 \mathrm{c}}$ Pascal and co-workers synthesized 8 by flash vacuum pyrolysis of phenanthrene-9,10-dicarboxylic anhydride, and assigned a $D_{3}$-symmetric structure (8a) based on X-ray crystallography. ${ }^{22 b}$ Pérez, Guitián and co-workers synthesized $\mathbf{8}$ by a Pd-catalyzed [2+2+2] cycloaddition of aryne, ${ }^{22 c}$ and a later conformational study of $\mathbf{8}$ revealed that, under these conditions, the metastable $C_{2}$ conformer (8b) is obtained. ${ }^{22 \mathrm{~d}}$ In $2003, \mathbf{8 b}$ was structurally characterized by X-ray crystallography by Wenger and coworkers. $^{22 \mathrm{e}}$ Experimentally, isomerization barriers of 11.7 $\mathrm{kcal} \cdot \mathrm{mol}^{-1}\left(\mathbf{8 b} \rightarrow \mathbf{8 b ^ { * }}\right.$, (i) in Figure 4(c)) and $26.2 \mathrm{kcal} \cdot \mathrm{mol}^{-1}$ $\left(\mathbf{8 b} \rightarrow \mathbf{8 a}\right.$, (ii) in Figure 4(c)) were determined. ${ }^{22 \mathrm{~d}}$ In 2011, a hexa-tert-butylated derivative of $\mathbf{8}$ was reported by Durola and co-workers. ${ }^{23}$ In 2017, another type of triple [5]helicene (9) was synthesized by Watanabe and co-workers via a photocyclization reaction. ${ }^{24}$ The calculated racemization barrier of 9 was reported as $29.5 \mathrm{kcal} \cdot \mathrm{mol}^{-1}$.

The racemization pathway of symmetric triple helicene $\mathbf{8}$ is shown in Figure 4(c). The most stable conformations of $\mathbf{8}$ are $D_{3}$-symmetric structures $\mathbf{8 a}$ and $\mathbf{8} \mathbf{a}^{*}$; the metastable $\mathrm{C}_{2}$-symmetric conformations $\mathbf{8 b}$ and $\mathbf{8 b ^ { * }}$ are $5.1 \mathrm{kcal} \cdot \mathrm{mol}^{-1}$ higher in energy. The enantiomerization from 8a to $\mathbf{8} \mathbf{a}^{*}$ proceeds via $\mathbf{8 a} \rightarrow \mathbf{8 b} \rightarrow \mathbf{8 b}^{*} \rightarrow \mathbf{8} \mathbf{a}^{*}$, where the rate-determining step is $\mathbf{8 a} \rightarrow \mathbf{T S}_{\mathbf{8 a b}}\left(\Delta G=32.1 \mathrm{kcal} \cdot \mathrm{mol}^{-1}\right)$. In this racemization pathway, the original chirality $(P, P, P)$ of $\mathbf{8 a}$ is lost upon transformation into the mirror symmetric $\left(C_{s}\right)$ transition state $\mathbf{T S}_{\mathbf{8 b b}}$. This is fundamentally different from the case of double helicene $\mathbf{1}$, where inversion of chirality occurs via passage through a metastable intermediate (1) $)$. Additionally, due to the higher interconversion barrier for $\mathbf{8 b} \rightarrow \mathbf{8 a}$, the racemization energy of the metastable conformation (8b) could be determined experimentally.

\section{Symmetric Quintuple Carbohelicenes}

Quintuple [6] helicene 10 was synthesized by Segawa, Itami, and co-workers in 2018, ${ }^{25}$ and 10 consists of eight isomers; i.e., four pairs of enantiomers. Even though 10 was initially expected as the product of a Scholl reaction of pentakis(biphenyl-2-yl)corannulene, this reaction generated warped nanographene ${ }^{26}$ due to the rapid formation of seven-membered rings. ${ }^{27}$ Alternatively, 11 was synthesized (a)
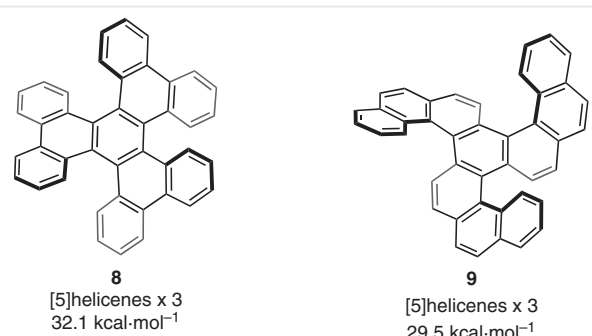

[5]helicenes $\times 3$ $29.5 \mathrm{kcal} \cdot \mathrm{mol}^{-1}$ $\left(27.4 \mathrm{kcal} \cdot \mathrm{mol}^{-1}\right)^{24}$
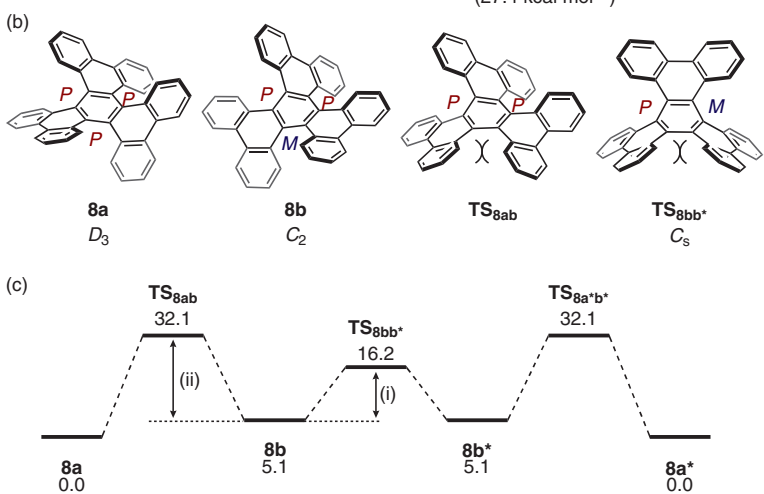

Figure 4 (a) Triple helicenes with racemization barriers. Experimentally determined racemization barrier is shown in parentheses. (b) Optimized conformers and transition structures of $\mathbf{8}$ with the helicity of the [5] helicene moieties ( $P$ or $M$ ). (c) Racemization pathway of $\mathbf{8}$ with relative Gibbs free energy values $\left(\mathrm{kcal} \cdot \mathrm{mol}^{-1}\right){ }^{4}$

from pentakis(2'-chlorobiphenyl-2-yl)corannulene by a Pdcatalyzed intramolecular cyclization. A single-crystal X-ray diffraction analysis of $\mathbf{1 0}$ confirmed a $C_{5}$-symmetric propeller-shaped structure (10a) with an identical helicity of the five [6] helicene moieties ( $P P P P P$ or $M M M M M)$.

The racemization of symmetric quintuple helicene $\mathbf{1 0}$ is shown in Figure 5(c). The enantiomerization pathway from 10a to 10a* proceeds via four ground states $\left(10 \mathbf{b}, 10 \mathbf{c}, 10 \mathbf{c}^{*}\right.$, and $\mathbf{1 0 b}^{*}$ ) and five transition states $\left(\mathbf{T S}_{\mathbf{1 0 a b}}, \mathbf{T S}_{\mathbf{1 0 b c}}, \mathbf{T S}_{\mathbf{1 0 c c}}\right.$,

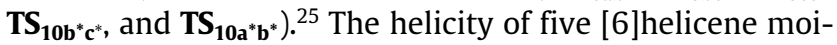
eties in 10a is inverted via the five TSs, whereby the highest TS on this route is $\mathbf{T S}_{\mathbf{1 0 a b}}\left(34.5 \mathrm{kcal} \cdot \mathrm{mol}^{-1}\right.$ relative to $\left.\mathbf{1 0 a}\right)$. This value is in good agreement with the experimentally determined racemization barrier of $10\left(34.2 \mathrm{kcal} \cdot \mathrm{mol}^{-1}\right)$.

\section{Symmetric Sextuple Carbohelicenes}

Sextuple [5]helicene 12 was independently reported by two groups in 2017. ${ }^{28}$ Tsurusaki, Kamikawa, and co-workers synthesized 12 via a Pd-catalyzed [2+2+2] cyclization reaction of a [5]helicene-based aryne. ${ }^{28 a}$ The cyclization reaction proceeded at room temperature and the metastable conformer 12d was isolated. A kinetic study revealed the isomerization barrier from $\mathbf{1 2 d}$ to $\mathbf{1 2} \mathbf{a}$ and the racemization barrier of 12a as $30.6 \mathrm{kcal} \cdot \mathrm{mol}^{-1}$ and $35.4 \mathrm{kcal} \cdot \mathrm{mol}^{-1}$, respectively. Coquerel, Gingras, and co-workers synthesized 

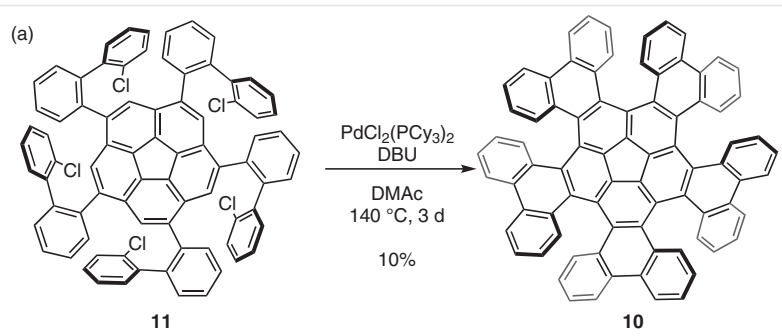

$10 \%$

(b)

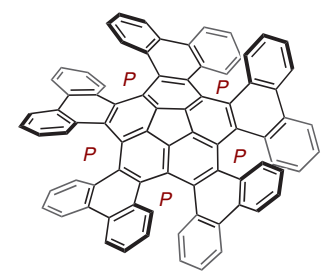

$\mathrm{C}_{5}^{10 \mathrm{a}}$

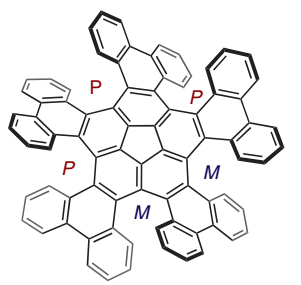

$10 \mathrm{c}$
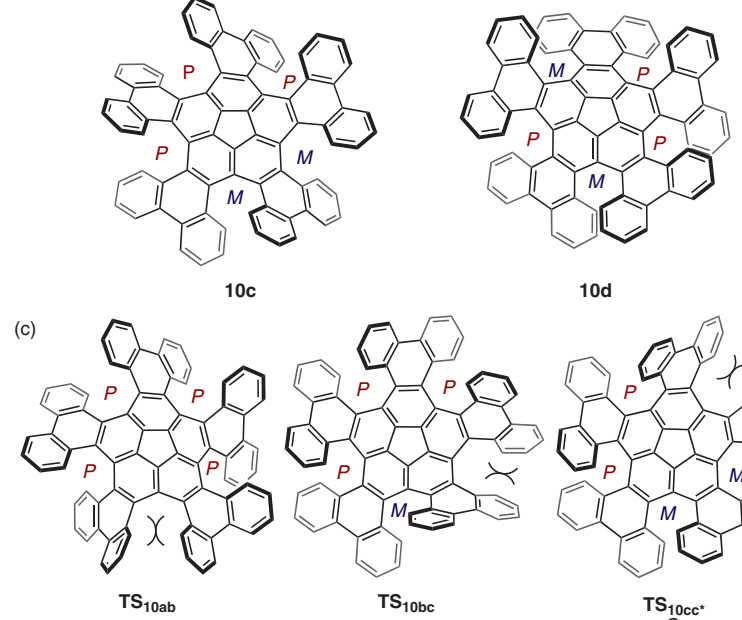

$10 \mathrm{~d}$
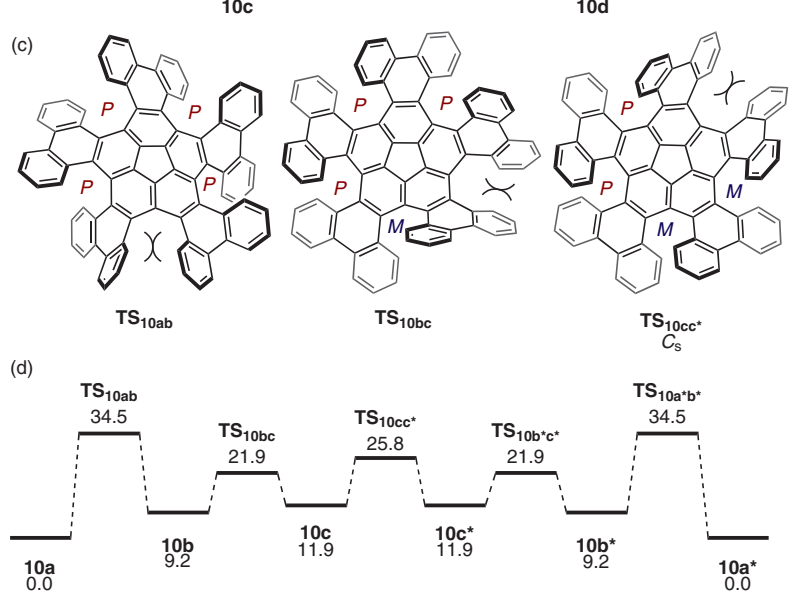

Figure 5 (a) Synthesis of $\mathbf{1 0}$ with racemization barrier. Experimentally determined racemization barrier is shown in parentheses. Abbreviations: $\mathrm{DMAC}=\mathrm{N}, \mathrm{N}$-dimethylacetamide; $\mathrm{DBU}=1,8$-diazabicyclo[5.4.0] undec-7-ene. (b) Optimized conformers of $\mathbf{1 0}(\mathbf{1 0 a}-\mathbf{d})$ with the helicity of the [6] helicene moieties $(P$ or $M)$. (c) Structures of $\mathbf{T S} \mathbf{S}_{10 \mathrm{ab}}, \mathbf{T S}_{\mathbf{1 0 b c}}$, and $\mathbf{T S} \mathbf{S}_{\mathbf{1 0 c c}}$. (d) The lowest racemization pathway of $\mathbf{1 0}$ with relative Gibbs free energy

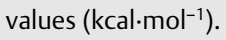

12 via the Ni-mediated homocoupling reaction of a dibrominated [5] helicene. ${ }^{28 b}$ Very recently, another type of sextuple helicene 13 has been reported by Wang and co-workers: ${ }^{29}$ the coronene-cored sextuple [7]helicene 13 was synthesized by a Scholl reaction of oligophenylene precursors, and X-ray diffraction analysis revealed a $D_{6}$-symmetric structure. The theoretically estimated racemization barrier of $13\left(52.1 \mathrm{kcal} \cdot \mathrm{mol}^{-1}\right)$ is higher than that of pristine [7]helicene $\left(42.0 \mathrm{kcal} \cdot \mathrm{mol}^{-1}\right)$. Due to the high barrier, the racemization of 13 was not observed, even after $12 \mathrm{~h}$ at $270{ }^{\circ} \mathrm{C}$.
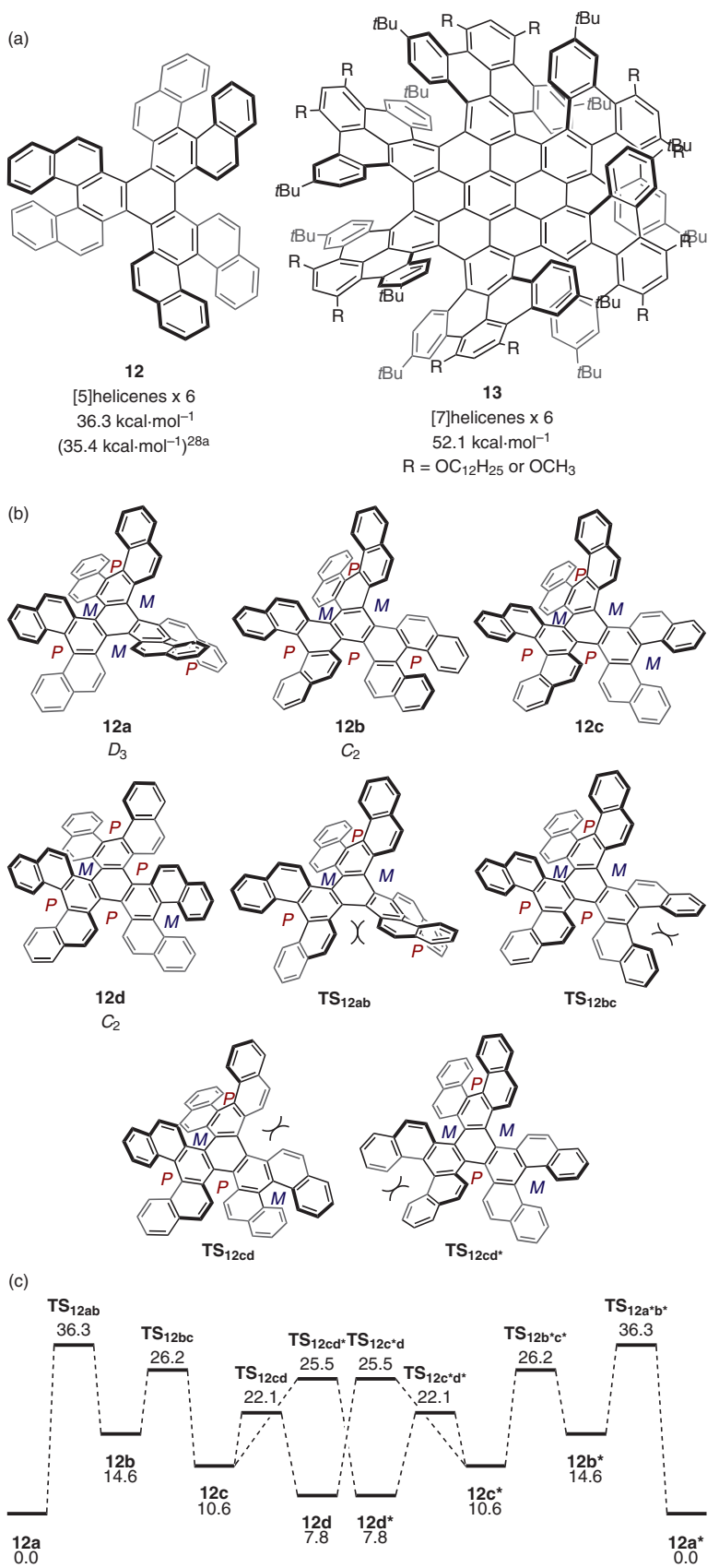

Figure 6 (a) Sextuple helicenes with racemization barriers. Experimentally determined racemization barrier is shown in parentheses. (b) Structures of conformers and TSs of $\mathbf{1 2}$ together with their symmetry. (c) The lowest racemization pathway of $\mathbf{1 2}$ with relative Gibbs free energy values $\left(\mathrm{kcal} \cdot \mathrm{mol}^{-1}\right)$. 
The racemization pathway of sextuple helicene $\mathbf{1 2}$ is shown in Figure 6(c). Combining the helicities of the six [5]helicene moieties affords 20 stereoisomers for 12; i.e., ten pairs of enantiomers. ${ }^{28 a}$ The most stable structure is $D_{3}$ symmetric conformation $\mathbf{1 2 a}$, in which the inner three [5]helicenes exhibit $M$ and the outer three [5]helicenes exhibit $P$ helicity. Moreover, two possible enantiomerization routes exist: 12a $\rightarrow$ TS $_{12 a b} \rightarrow 12 b \rightarrow$ TS $_{12 b c} \rightarrow 12 c \rightarrow$ TS $_{12 c d} \rightarrow$ 12d $\rightarrow$ TS $_{12 c^{*} d} \rightarrow 12 c^{*}\left(\right.$ or $12 c \rightarrow$ TS $_{12 d^{*}} \rightarrow 12 d^{*} \rightarrow$ TS $_{12 c^{*} d^{*}} \rightarrow$ 12c $\left.^{*}\right) \rightarrow$ TS $_{12 b^{*} c^{*}} \rightarrow$ 12b $^{*} \rightarrow$ TS $_{12 a^{*} b^{*}} \rightarrow$ 12a* $^{*}$. The rate-determining step is $\mathbf{1 2 a} \rightarrow \mathbf{T S}_{\mathbf{1 2 a b}}\left(\Delta G=36.3 \mathrm{kcal} \cdot \mathrm{mol}^{-1}\right)$, and its energy barrier is higher than that of pristine [5]helicene owing to the steric hindrance of neighboring [5]helicene moieties.

\section{Conclusions and Perspective}

In this account, we focused on the synthesis and structures of symmetric multiple carbohelicenes and their isomerization pathways. For the synthesis of multiple helicenes with further multiplicity, it is necessary to establish new synthetic strategies to overcome the intermolecular steric hindrance inherent to multiple helicenes.

We propose a novel series of multiple helicenes inspired by 10. As already proposed by Pascal and co-workers in $1999,{ }^{22 b}$ symmetric multiple helicenes can be designed by fusing benzene rings dendritically onto a central benzene ring (Figure 7(a)). Triple [5] helicene $\mathbf{8}$ can be considered as a benzene ring that contains six fused benzene rings, and the extension of $\mathbf{8}$ by additional twelve benzene rings affords sextuple helicene $\mathbf{1 4}$ with three [5]helicenes and three [7] helicenes. On the other hand, using [ $n$ ]circulenes as central cores as in, for example, quintuple helicene 10, multiple helicenes with various multiplicities can be designed (Figure 7(b)). Sextuple [6] helicene $\mathbf{1 5}$ is obtained from the introduction of six phenanthrene moieties into [6]circulene (coronene). According to preliminary calculations, ${ }^{4}$ the most stable structure of $\mathbf{1 5}$ is the $D_{3 d^{-}}$-symmetric structure. Septuple [6]helicene $\mathbf{1 6}$ and octuple [6] helicene 17 can also be designed by a $\pi$-extension of [7]- and [8]circulenes, respectively, and theoretical calculations suggest highly warped structures. While a coronene-cored sextuple [4] helicene has already been reported, ${ }^{30}$ such complex three-dimensional $\pi$-systems remain difficult to construct. The further development of multiple helicene chemistry thus requires improvements of the synthetic methods for the generation of such highly strained molecules, before multiple helicenes with unique structural features may potentially be use as chiral materials in future.
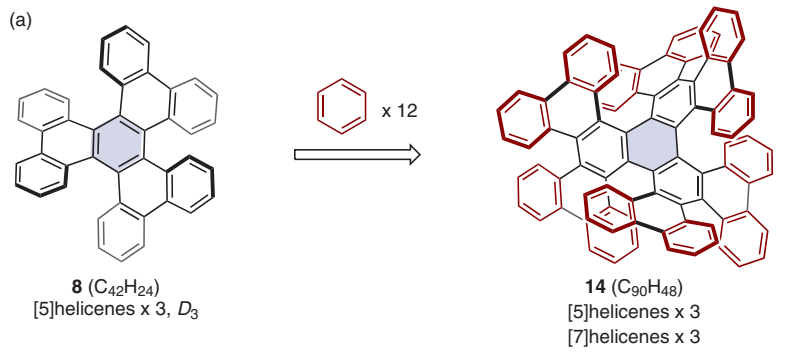

(b)
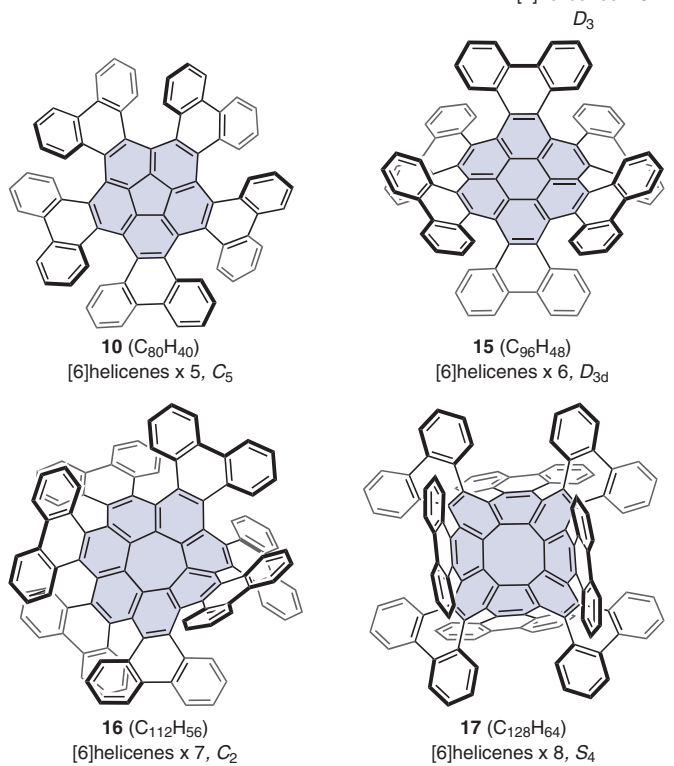

Figure 7 Design of multiple helicenes; (a) Optimized stricture of triple helicene 8 and sextuple helicene 14. (b) Optimized structures of multiple helicenes with $[n]$ circulene cores.

\section{Funding Information}

This work was supported by the ERATO program from JST (JPMJER1302 to K.I.), the Funding Program for KAKENHI from MEXT (JP16K05771 to Y.S.), a grant-in-aid for Scientific Research on Innovative Areas ' $\pi$-Figuration' from JSPS (JP17H05149 to Y.S.), and the Noguchi Institute (to Y.S.). K.K. thanks IGER Program in Green Natural Sciences, Nagoya University and a JSPS fellowship for young scientists. Calculations were performed using the resources of the Research Center for Computational Science, Okazaki, Japan. ITbM is supported by the World Premier International Research Center Initiative (WPI), Japan.

\section{References and Notes}

(1) For reviews on helicenes, see: (a) Helicene Chemistry From Synthesis to Applications; Chen, C.-F.; Sheb, Y., Eds.; Springer: Berlin, 2017. (b) Shen, Y.; Chen, C.-F. Chem. Rev. 2012, 112, 1463. (c) Gingras, M. Chem. Soc. Rev. 2013, 42, 968. (d) Gingras, M.; Félix, G.; Peresutti, R. Chem. Soc. Rev. 2013, 42, 1007. (e) Gingras, M. Chem. Soc. Rev. 2013, 42, 1051. (f) Hasan, M.; Brovrkoovvko, V. Symmetry 2018, 10, 10.

(2) Cahn, R. S.; Ingold, C.; Prelog, V. Angew. Chem. Int. Ed. Engl. 1966, 5,385 . 
(3) For isomerization barriers of carbo[n]helicenes, see: (a) Janke, R. H.; Haufe, G.; Würthwein, E.-U.; Borkent, J. H. J. Am. Chem. Soc. 1996, 118, 6031. (b) Grimme, S.; Peyerimhoff, S. D. Chem. Phys. 1996, 204, 411. (c) Goedicke, C.; Stegemeyer, H. Tetrahedron Lett. 1970, 937. (d) Martin, R. H.; Marchant, M. J. Tetrahedron Lett. 1972, 3707. (e) Martin, R. H.; Marchant, M. J. Tetrahedron 1973, 30, 347. (f) Martin, R. H.; Marchant, M. J. Tetrahedron 1974, 30, 347. (g) Ravat, P.; Hinkelmann, R.; Steinebrunner, D.; Prescimone, A.; Bodoky, I.; Jurícěk, M. Org. Lett. 2017, 19, 3707. (h) Barroso, J.; Cabellos, J. L.; Pan, S.; Murillo, F.; Zarate, X.; Fernandez-Herrera, M. A.; Merino, G. Chem. Commun. 2018, 188.

(4) For this study, the energy values were calculated or re-calculated at the B3LYP/6-31G (d) level of theory.

(5) For long carbohelicenes, see: (a) Flammang-Barbieux, M.; Nasielski, J.; Martin, R. H. Tetrahedron Lett. 1967, 743. (b) Martin, R. H.; Morren, G.; Schurter, J. J. Tetrahedron Lett. 1969, 3683. (c) Martin, R. H.; Baes, M. Tetrahedron 1975, 31, 2135. (d) Sehnal, P.; Stará, I. G.; Šaman, D.; Tichý, M.; Míšek, J.; Cvačka, J.; Rulíšek, L.; Chocholoušová, J.; Vacek, J.; Goryl, G.; Szymonski, M.; Císařová, I.; Starý, I. Proc. Natl. Acad. Sci. USA 2009, 106, 13169. (e) Mori, K.; Murase, T.; Fujita, M. Angew. Chem. Int. Ed. 2015, 54, 6847. (f) Murayama, K.; Shibata, Y.; Sugiyama, H.; Uekusa, H.; Tanaka, K. J. Org. Chem. 2017, 82, 1136. (g) Satoh, M.; Shibata, Y.; Tanaka, K. Chem. Eur.J. 2018, 24, 5434.

(6) For laterally extended helicenes, see: (a) Vingiello, F. A.; Henson, P. D. J. Org. Chem. 1965, 30, 2842. (b) Laarhoven, W. H.; Cuppen, Th. J. H. M.; Nivard, R. J. F. Tetrahedron 1970, 26, 4865. (c) Laarhoven, W. H.; Nivard, R. J. F. Tetrahedron 1976, 32, 2445. (d) Jančařík, A.; Rybáček, J.; Cocq, K.; Chocholoušová, J. V.; Vacek, J.; Pohl, R.; Bednárová, L.; Fiedler, P.; Císařová, I.; Stará, I. G.; Starý, I. Angew. Chem. Int. Ed. 2013, 52, 9970. (e) Bédard, A.C.; Vlassova, A.; Hernandez-Perez, A. C.; Bessette, A.; Hanan, G. S.; Heuft, M. A.; Collins, S. K. Chem. Eur. J. 2013, 19, 16295. (f) Hu, J.-Y.; Paudel, A.; Seto, N.; Feng, X.; Era, M.; Matsumoto, T.; Tanaka, J.; Elsegood, M. R. J.; Redshaw, C.; Yamato, T. Org. Biomol. Chem. 2013, 11, 2186. (g) Buchta, M.; Rybáček, J.; Jančařík, A.; Kudale, A. A.; Buděšínský, M.; Chocholoušová, J. V.; Vacek, J.; Bednárová, L.; Císařová, I.; Bodwell, G. J.; Starý, I.; Stará, I. G. Chem. Eur. J. 2015, 21, 8910. (h) Daigle, M.; Miao, D.; Lucotti, A.; Tommasini, M.; Morin, J.-F. Angew. Chem. Int. Ed. 2017, 56, 6213. (i) Nakakuki, Y.; Hirose, T.; Sotome, H.; Miyasaka, H.; Matsuda, K. J. Am. Chem. Soc. 2018, 140, 4317.

(7) For thiahelicenes, see: (a) Yamada, K.; Ogashiwa, S.; Tanaka, H.; Nakagawa, H.; Kawazura, H. Chem. Lett. 1981, 343. (b) Caronna, T.; Sinisi, R.; Catellani, M.; Malpezzi, L.; Meille, S. V.; Mele, A. Chem. Commun. 2000, 1139. (c) Miyasaka, M.; Pink, M.; Olankitwanit, A.; Rajca, S.; Rajca, A. Org. Lett. 2012, 14, 3076.

(8) For azahelicenes, see: (a) Bazzini, C.; Brovelli, S.; Caronna, T.; Gambarotti, C.; Giannone, M.; Macchi, P.; Meinard, F.; Mele, A.; Panzeri, W.; Recupero, F.; Sironi, A.; Tubino, R. Eur. J. Org. Chem. 2005, 1247. (b) Nakano, K.; Hidehira, Y.; Takahashi, K.; Hiyama, T.; Nozaki, K. Angew. Chem. Int. Ed. 2005, 44, 7136. (c) Goto, K.; Yamaguchi, R.; Hiroto, S.; Ueno, H.; Kawai, T.; Shinokubo, H. Angew. Chem. Int. Ed. 2012, 51, 10333. (d) Chocholoušová, J. V.; Vacek, J.; Andronova, A.; Míšek, J.; Songis, O.; Šámal, M.; Stará, I. G.; Meyer, M.; Bourdillon, M.; Pospíšil, L.; Starý, I. Chem. Eur. J. 2014, 20, 877.

(9) For other representative heterohelicenes, see: (a) Dreher, S. D.; Weix, D. J.; Katz, T. J. J. Org. Chem. 1999, 64, 3671. (b) Fukawa, N.; Osaka, T.; Noguchi, K.; Tanaka, K. Org. Lett. 2010, 12, 1324. (c) Hatakeyama, T.; Hashimoto, S.; Nakamura, M. Org. Lett.
2011, 13, 2130. (d) Hatakeyama, T.; Hashimoto, S.; Oba, T.; Nakamura, M. J. Am. Chem. Soc. 2012, 134, 19600. (e) Nakano, K.; Oyama, H.; Nishimura, Y.; Nakasako, S.; Nozaki, K. Angew. Chem. Int. Ed. 2012, 51, 695. (f) Oyama, H.; Nakano, K.; Harada, T.; Kuroda, R.; Naito, M.; Nobusawa, K.; Nozaki, K. Org. Lett. 2013, 15, 2104. (g) Gouin, J.; Bürgi, T.; Guénée, L.; Lacour, J. Org. Lett. 2014, 16, 3800. (h) Miyamoto, F.; Nakatsuka, S.; Yamada, K.; Nakayama, K.; Hatakeyama, T. Org. Lett. 2015, 17, 6158. (i) Sundar, M. S.; Bedekar, A. V. Org. Lett. 2015, 17, 5808. (j) Murayama, K.; Oike, Y.; Furumi, S.; Takeuchi, M.; Noguchi, K.; Tanaka, K. Eur. J. Org. Chem. 2015, 1409. (k) Schickedanz, K.; Trageser, T.; Bolte, M.; Lerner, H.-W.; Wagner, M. Chem. Commun. 2015, 15808. (l) Yamamoto, Y.; Sakai, H.; Yuasa, J.; Araki, Y.; Wada, T.; Sakanoue, T.; Takenobu, T.; Kawai, T.; Hasobe, T. J. Phys. Chem. C 2016, 120, 7421. (m) Wang, T.; Zhang, H.; Pink, M.; Olankitwanit, A.; Rajca, S.; Rajca, A. J. Am. Chem. Soc. 2016, 138, 7298 .

(10) For a review on multiple helicenes, see: Li, C.; Yang, Y.; Miao, Q. Chem. Asian J. 2018, 13, 884.

(11) For multiple helicenes that contain five-membered rings, see: (a) Dutta, A. K.; Linden, A.; Zoppi, L.; Baldridge, K. K.; Siegel, J. S. Angew. Chem. Int. Ed. 2015, 54, 10792. (b) Geng, X.; Mague, J. T.; Pascal, R. A. Jr. J. Org. Chem. 2015, 80, 4824. (c) Gu, X.; Xu, X.; Li, H.; Liu, Z.; Miao, Q. J. Am. Chem. Soc. 2015, 137, 16203. (d) Ma, J.; Liu, J.; Baumgarten, M.; Fu, Y.; Tan, Y.-Z.; Schellhammer, K. S.; Ortmann, F.; Cuniberti, G.; Komber, H.; Berger, R.; Müllen, K.; Feng, X. Angew. Chem. Int. Ed. 2017, 56, 3280. (e) Liu, J.; Ma, J.; Zhang, K.; Ravat, P.; Machata, P.; Avdoshenko, S.; Hennersdorf, F.; Komber, H.; Pisula, W.; Weigand, J. J.; Popov, A. A.; Berger, R.; Müllen, K.; Feng, X. J. Am. Chem. Soc. 2017, 139, 7513.

(12) For multiple heterohelicenes, see: (a) Zhang, Y.; Petersen, J. L.; Wang, K. K. Org. Lett. 2007, 9, 1025. (b) Nakamura, K.; Furumi, S.; Takeuchi, M.; Shibuya, T.; Tanaka, K. J. Am. Chem. Soc. 2014, 136, 5555. (c) Sakamaki, D.; Kumano, D.; Yashima, E.; Seki, S. Angew. Chem. Int. Ed. 2015, 54, 5404. (d) Katayama, T.; Nakatsuka, S.; Hirai, H.; Yasuda, N.; Kumar, J.; Kawai, T.; Hatakeyama, T. J. Am. Chem. Soc. 2016, 138, 5210. (e) Wang, X.Y.; Wang, X.-C.; Narita, A.; Wagner, M.; Cao, X.-Y.; Feng, X.; Müllen, K. J. Am. Chem. Soc. 2016, 138, 12783. (f) Wang, X.-Y.; Narita, A.; Zhang, W.; Feng, X.; Müllen, K. J. Am. Chem. Soc. 2016, 138, 9021. (g) Krzeszewski, M.; Kodama, T.; Espinoza, E. M.; Vullev, V. I.; Kubo, T.; Gryko, D. T. Chem. Eur. J. 2016, 22, 16478. (h) Fujikawa, T.; Segawa, Y.; Itami, K.J. Am. Chem. Soc. 2016, 138, 3587. (i) Fujikawa, T.; Mitoma, N.; Wakamiya, A.; Saeki, A.; Segawa, Y.; Itami, K. Org. Biomol. Chem. 2017, 15, 4697.

(13) For other polycyclic arenes that contain helicene moieties, see: (a) Peña, D.; Cobas, A.; Pérez, D.; Guitián, E.; Castedo, L. Org. Lett. 2003, 5, 1863. (b) Yanney, M.; Fronczek, F. R.; Henry, W. P.; Beard, D. J.; Sygula, A. Eur. J. Org. Chem. 2011, 6636. (c) Eversloh, C. L.; Liu, Z.-H.; Müller, B.; Stangl, M.; Li, C.; Müllen, K. Org. Lett. 2011, 13, 5528. (d) Xiao, S.; Kang, S. J.; Wu, Y.; Ahn, S.; Kim, J. B.; Loo, Y.-L.; Siegrist, T.; Steigerwald, M. L.; Li, H.; Nuckolls, C. Chem. Sci. 2013, 4, 2018. (e) Arslan, H.; Uribe-Romo, F. J.; Smith, B. J.; Dichtel, W. R. Chem. Sci. 2013, 4, 3973. (f) Kashihara, H.; Asada, T.; Kamikawa, K. Chem. Eur. J. 2015, 21, 6523. (g) Bock, H.; Huet, S.; Dechambenoit, P.; Hillard, E. A.; Durola, F. Eur. J. Org. Chem. 2015, 1033. (h) Dong, M.; Fu, H.; Xiao, C.; Meng, X.; Winands, T.; Ma, W.; Wei, W.; Fan, B.; Huo, L.; Doltsinis, N. L.; Li, Y.; Sun, Y.; Wang, Z. J. Am. Chem. Soc. 2016, 32, 10184. (i) Yang, Y.; Yuan, L.; Shan, B.; Liu, Z.; Miao, Q. Chem. Eur. J. 2016, 22, 18620. (j) Ferreira, M.; Naulet, G.; Gallardo, H.; Dechambenoit, P.; Bock, H.; Durola, F. Angew. Chem. Int. Ed. 2017, 56, 3379.

(14) Clar, E.; Ironside, C. T.; Zander, M. J. Chem. Soc. 1959, 142. 
(15) Fujimaki, Y.; Takekawa, M.; Fujisawa, S.; Ohshima, S.; Sakamoto, Y. Polycyclic Aromat. Compd. 2004, 24, 107.

(16) Marom, H.; Pogodin, S.; Agranat, I. Polycyclic Aromat. Compd. 2007, 27, 295.

(17) (a) Laarhoven, W. H.; Cuppen, Th. J. H. M. Tetrahedron Lett. 1971, 163. (b) Laarhoven, W. H.; de Jong, M. H. Recl. Trav. Chim. PaysBas 1973, 92, 651.

(18) Martin, R. H.; Eyndels, C.; Defay, N. Tetrahedron 1974, 30, 3339.

(19) Kashihara, H.; Asada, T.; Kamikawa, K. Chem. Eur. J. 2015, 21, 6523.

(20) Fujikawa, T.; Segawa, Y.; Itami, K. J. Am. Chem. Soc. 2015, 137, 7763.

(21) Hu, Y.; Wang, X.-Y.; Peng, P.-X.; Wang, X.-C.; Cao, X.-Y.; Feng, X.; Müllen, K.; Narita, A. Angew. Chem. Int. Ed. 2017, 56, 3374.

(22) (a) Hacker, N. P.; McOmie, J. F. W.; Meunier-Piret, J.; Van Meerssche, M. J. Chem. Soc., Perkin Trans. 1 1982, 19. (b) Barnett, L.; Ho, D. M.; Baldridge, K. K.; Pascal, R. A. Jr. J. Am. Chem. Soc. 1999, 121, 727. (c) Peña, D.; Pérez, D.; Guitiań, E.; Castedo, L. Org. Lett. 1999, 1, 1555. (d) Peña, D.; Cobas, A.; Pérez, D.;
Guitián, E.; Castedo, L. Org. Lett. 2000, 2, 1629. (e) Bennett, A. A.; Kopp, M. R.; Wenger, E.; Willis, A. C. J. Organomet. Chem. 2003, $667,8$.

(23) Anirban, P.; Dechambenoit, P.; Bock, H.; Durola, F. Angew. Chem. Int. Ed. 2011, 50, 12582.

(24) Saito, H.; Uchida, A.; Watanabe, S. J. Org. Chem. 2017, 82, 5663.

(25) Kato, K.; Segawa, Y.; Scott, L. T.; Itami, K. Angew. Chem. Int. Ed. 2018, 57, 1337.

(26) Kawasumi, K.; Zhang, Q.; Segawa, Y.; Scott, L. T.; Itami, K. Nat. Chem. 2013, 5, 739 .

(27) Kato, K.; Segawa, Y.; Scott, L. T.; Itami, K. Chem. Asian J. 2015, 10 , 1635.

(28) (a) Hosokawa, T.; Takahashi, Y.; Matsushima, T.; Watanabe, S.; Kikkawa, S.; Azumaya, I.; Tsurusaki, A.; Kamikawa, K. J. Am. Chem. Soc. 2017, 139, 18512. (b) Berezhnaia, V.; Roy, M.; Vanthuyne, N.; Villa, M.; Naubron, J.-V.; Rodriguez, J.; Coquerel, Y.; Gingra, M. J. Am. Chem. Soc. 2017, 139, 18508.

(29) Zhu, Y.; Xia, Z.; Cai, Z.; Yuan, Z.; Jiang, N.; Li, T.; Wang, Y.; Guo, X.; Li, Z.; Ma, S.; Zhong, D.; Li, Y.; Wang, J.J. Am. Chem. Soc. 2018, $140,4222$.

(30) Clar, E.; Stephen, J. F. Tetrahedron 1965, 21, 467. 